\title{
A LEI 10.639/03 NO ENSINO DE CIÊNCIAS: uma proposta decolonial para o currículo de Química
}

\author{
lago Vilaça de Carvalho' \\ Bruno Andrade Pinto Monteiro2 \\ Fernanda Antunes Gomes da Costa ${ }^{3}$
}

\section{RESUMO}

A Lei 10.639/03 completa 16 anos de existência, e com isto, 16 anos de obrigatoriedade do ensino de História e da Cultura Afro-brasileira e Africana em todas as escolas do Brasil. Com base nisto, este trabalho se estrutura, então, a partir da provocação decolonial ao currículo de Química, a fim de estudar os desdobramentos da colonialidade no contexto educacional. Para isso, são tecidas considerações acerca da implementação da lei citada nos livros didáticos, principais ferramentas didáticas dos professores, através de uma análise qualitativa da abordagem da temática por esses livros. Diante dos resultados desta análise, buscamos compreender a relação entre livros, currículo e colonialidade. Ao nos depararmos com livros baseados em um currículo predominantemente eurocêntrico, realizamos, como disposição final, uma proposta de currículo decolonial contextualizado que contemple as culturas tradicionais, em particular, a afro-brasileira. Neste sentido, esperamos que, a partir do desenvolvimento de um currículo afrocentrado seja possível atingir a efetivação da Lei 10.639/03 e combater os perversos efeitos do racismo na sociedade brasileira.

Palavras-chave: Lei 10.630/03. Decolonialidade. Ensino de Química.

LAW 10.639/03 IN SCIENCE TEACHING: a decolonial proposal for the Chemistry curriculum

\begin{abstract}
1 Graduado em Licenciatura em Química (UFRJ). Mestrando em Educação em Ciências e Saúde (UFRJ), Campus Macaé/ Macaé/RJ/Brasil. Orcid iD: http://orcid.org/0000-0002-44154226. E-mail: iago.v.carvalho@gmail.com

2 Doutor em Educação em Ciências e Saúde (UFRJ). Professor do Programa de PósGraduação em Educação em Ciências e Saúde da Universidade Federal do Rio de Janeiro. Professor do Mestrado Profissional em Ensino de Química da Universidade Federal do Rio de Janeiro. Professor Adjunto da UFRJ - Campus Macaé. Orcid iD: https://orcid.org/0000-00021861-3310. E-mail: nandantunes80@gmail.com

3 Doutorado em Letras Vernáculas - Literaturas Africanas de Língua Portuguesa (UFRJ). Professora do Programa de Pós-Graduação em Educação em Ciências e Saúde da Universidade Federal do Rio de Janeiro (NUTES - UFRJ). Professora Adjunta dos cursos de Licenciatura da UFRJ - Campus Macaé. Orcid iD: https://orcid.org/0000-0001-8933-5816. Email: bpmonteiro@gmail.com
\end{abstract}


Law 10.639/03 completes 16 years of existence, and it is with this, 16 years of obligatoriness of teaching of Afro-Brazilian and African History and Culture in all schools in Brazil. Based on this, this is the framework work from the decolonial provocation to the Chemistry curriculum to study on the unfolding of coloniality in the educational context. For this, cosiderations are made about the implementation of the cited law in the textbooks, the teachers main didactic tools, through a qualitative analysis of the approach of the question by these books. Given the results of this analysis, it seeks to understand the relationship between books, curriculum and coloniality. When we come across books based in a predominantly Eurocentric curriculum, we performed as final provision a contextualized curriculum proposal that considers the traditional cultures, particularly the Afro-Brazilian one. Thus, we hope that through the development of an Afrocentric curriculum the effective implementation of Law 10.639/03 and the combat to perverse effects of racism in Brazilian society will be possible.

Keywords: Law 10.639/03. Decoloniality. Teaching Chemistry.

\section{LA LEY 10.639/03 EN LA ENSEÑANZA DE CIENCIAS: una propuesta decolonial para el currículo de Química}

\section{RESUMEN}

La Ley 10.639/03 completa 16 años de existencia, y con ello, 16 años de obligatoriedad de la enseñanza de Historia y de la Cultura Afro-brasileña y Africana en todas las escuelas de Brasil. Con base en esto, este trabajo se estructura, entonces, a partir de la provocación decolonial al currículo de Química a fin de estudiar los desdoblamientos de la colonialidad en el contexto educativo. Para ello, se toman consideraciones acerca de la aplicación de la ley en los libros didácticos, principales herramientas didácticas de los profesores, a través de un análisis cualitativo del abordaje de la temática por esos libros. Ante los resultados de este análisis, buscamos comprender la relación entre libros, currículo y colonialidad. Al encontrarse libros basados en un currículo predominantemente eurocêntrico, realizamos, como disposición final, una propuesta de currículo decolonial contextualizado que contemple las culturas tradicionales, en particular, la afrobrasileña. En este sentido, esperamos que a partir del desarrollo de un currículum afrocentrado sea posible alcanzar la efectividad de la Ley 10.639/03 y combatir los perversos efectos del racismo en la sociedad brasileña.

Palabras clave: Ley10.639/03. Decolonialidad. Enseñanza de Química.

\section{INTRODUÇÃO}

Só um mundo novo nós queremos: o que tenha tudo de novo e nada de mundo.

(COUTO, 2013, p.174)

Mediante a frase de Mia Couto (2013), inauguramos o presente trabalho fazendo uma reflexão: acreditar que a busca pela renovação das

Revista Exitus, Santarém/PA, Vol. 9, № 5, p. 47 - 76, Edição Especial 2019. 
esperanças humanas e o vigor pelo novo e inédito criam na humanidade a expectativa sobre o inexplorado, pelo intangível. Seria condizente com esta expectativa de renovação que o vislumbre desse novo incitasse a renúncia aos embargos pretéritos da sociedade, ou seja, uma renúncia ao mundo. Mais do que isso, ao que se entende por mundo.

As bases da sociedade capitalista ocidental também anseiam uma inovação, no entanto, estas bases são fundamentadas no ideal europeu expansionista do século XV. Este ideal resulta na conquista do Novo Mundo, termo cujo significado não possui nada de novo, apenas de mundo - em contradição à epígrafe supracitada. Colocando em cheque esta oposição, observa-se a necessidade da revisita a estes pressupostos dissonantes.

O processo colonizatório surge

como um implante ultramarino da expansão européia que não existe para si mesmo, mas para gerar lucros exportáveis pelo exercício da função de provedor colonial de bens para o mercado mundial através do desgaste da população que recruta no país ou importa (RIBEIRO, 1995, P. 20).

O que queremos dizer é que o projeto semeado nos países colonizados é inserido numa lógica de dominação, a partir da imposição dos colonizadores, que nada criam se não lucrativas fontes de recursos financeiros.

Caminhando para o contexto educacional, o que se pretende propor é que se faça possivel desenvolver métodos e caminhos docentes para a catálise de ideias inovadoras do pensar educativo. Ideias novas. Para tal, este estudo enxerga a efetivação da Lei 10.639/034 como proposta decolonial no ensino de Química, para refletir acerca de problemas nos processos educativos presentes no currículo da disciplina.

Esta narrativa nasce do confronto entre a dificuldade de aplicação da Lei 10.639/03 e a estrutura curricular, ambas claramente presentes nos livros didáticos. Assim, esta proposição se estrutura em três momentos.

\footnotetext{
${ }^{4}$ Conhecida extraoficialmente como Lei das Africanidades, altera a Lei no 9.394, de 20 de dezembro de 1996, que estabelece as diretrizes e bases da educação nacional, para incluir no currículo oficial da Rede e Ensino a obrigatoriedade da temática 'História e Cultura AfroBrasileira' (BRASIL, 2003).
}

Revista Exitus, Santarém/PA, Vol. 9, № 5, p. 47 - 76, Edição Especial 2019. 
Primeiramente, iniciaremos uma provocação acerca do currículo escolar tradicional, traçando um paralelo com a (de)colonialidade.

Num segundo momento, realizaremos uma análise qualitativa dos livros didáticos de Química, a partir de considerações acerca dos referenciais teóricos estudados. Este passo da pesquisa tem por finalidade encontrar traços desta colonialidade que impedem a efetivação da Lei 10.639/03 no ensino de Química.

Por último, utilizando algumas teorias do campo da decolonialidade, pretende-se buscar a reflexão acerca das limitações impostas pelo currículo na abordagem dos temas que dizem respeito às culturas africanas e afrobrasileiras a partir da apresentação propostas curriculares elaboradas para o ensino de Química.

\section{DA COLONIALIDADE AO CURRÍCULO DE QUÍMICA}

O conceito Colonialidade é trazido por Quijano (2002) através do que ele chama de colonialidade do poder, definindo, assim, as formas de classificação social, de acordo com os padrões atuais de poder da população mundial, a partir da ideia de raça. Para o autor:

Essa idéia e a classificação social e baseada nela (ou "racista") foram originadas há 500 anos junto com América, Europa e o capitalismo. São a mais profunda e perdurável expressão da dominação colonial e foram impostas sobre toda a população do planeta no curso da expansão do colonialismo europeu (QUIJANO, 2002, p. 4).

Este padrão está apoiado nas bases do trabalho e da exploração da mão-de-obra, sendo difundido por todas as áreas da vida social. Para o autor, a colonialidade do poder ainda está presente na atualidade, pois "faz parte do contexto global dentro do qual ocorrem os processos que afetam todos os espaços concretos de dominação" (QUIJANO, 2002, p. 13). Esta presença se dá pelos processos de nacionalização e democratização dos Estados modernos na Europa Ocidental até o século XX, que impõem mundialmente a colonialidade do poder. Como consequência disto, o mundo colonizado vê o seu próprio processo de democratização das 
relações sociais e sua expressão nacional, na sociedade e no Estado, obstruídos pela colonialidade (QUIJANO, 2002).

Em contrapartida, o que entendemos como Modernidade, que para Dussel (2000, p. 50) "nasce realmente em 1492", ou pensamento moderno, se institui a partir da pós-colonialidade, ou pensamento pós-colonial. Segundo Ballestrin (2013), a pós-colonialidade se baseia em duas noções: a de que este se refere ao período da história que sucede a independência das nações do terceiro mundo, em seus processos de descolonização; e a de que este representa uma gama de pressupostos teóricos no campo da literatura e cultura que passaram a ser estudados em universidades americanas e inglesas a partir da década de 1980 (BALLESTRIN, 2013).

A partir da primeira definição, que compete aos estudos das ciências sociais (e que discutiremos neste trabalho), podemos dizer que tais processos de independência não foram capazes de encerrar os conflitos coloniais que nascem da produção de identidades individuais e coletivas nas culturas colonizadas, principalmente, no que diz respeito às culturas africanas e indígenas. Estas identidades geradas por estes conflitos coloniais são marcadas pela dicotomia entre múltiplos sujeitos, interlocutores na dialética da experiência social. Tais sujeitos se definem como resposta à negação do outro - ambos não existem completos, mas sim, produzem-se a partir da incompletude do outro (FANON, 1968; FREIRE, 2011).

Para Fanon, no contexto africano, "o colono e o colonizado são velhos conhecidos" já que a situação de colonizado só é construída, e continua a ser, no momento em que o colono lhe nega sua verdade e seus bens e the impõe o sistema colonial. Já para Freire (2016), no contexto indígena das Américas5, o colonizador possui uma presença predatória, "um incontido gosto de sobrepor-se, não só ao espaço físico, mas ao histórico e cultural dos indivíduos" (2016, p. 83), colocando-os em condição desumana na intenção de "destruir a identidade cultural dos nacionais" (2016, p. 83).

\footnotetext{
${ }^{5}$ Apesar de mencionarmos o contexto indígena, não nos aprofundaremos no tema, focando nossa análise apenasno contexto cultural africano e afro-brasileiro. No entanto, entendemos a importância do reconhecimento e denúncia e combate aos resultados devastadores da colonização sobre os povos indígenas.
}

Revista Exitus, Santarém/PA, Vol. 9, № 5, p. 47 - 76, Edição Especial 2019. 
É interessante notar que esse padrão de negação se faz presente dentro de uma lógica social local e passa então a ser implementado por outras nações. Este processo pode ser entendido como globalização, que sob as palavras de Santos (2009b, p. 12), se define como "processo pelo qual determinada condição ou entidade local estende a sua influência a todo o globo". Segundo o autor, ainda, "ao fazê-lo, desenvolve a capacidade de designar como local outra condição social ou entidade rival" (SANTOS, 2009b, p. 12). Assim, esta condição ou entidade atinge status global e passa a se destacar em detrimento das condições e entidades outras.

Assim, os países em desenvolvimento do Hemisfério Sul vivem um cenário de constante aumento das tensões resultantes destas identidades, que geram dinâmicas sociais particulares do sistema de sociedade ocidental. Este modelo difundido pelos processos colonizatórios durante o imperialismo, continua sendo importado pelas nações colonizadas até os dias atuais.

Frente a este aspecto de manutenção dos laços exploratórios nas esferas econômica, social, política e cultural, é possível observar-los também na esfera do conhecimento. Mais do que isso, estes laços estão presentes na colonização dos processos de produção do conhecimento.

Tendo isso em vista, Mignolo (2008), propõe a desvinculação epistêmica com as teorias fundamentalmente europeias, no que chama de desobediência epistêmica. Dessa forma, para superar estas amarras imperialistas, faz-se necessário o desenvolvimento de epistemologias do sul, que germinem, principalmente, dos costumes dos povos tradicionais, para abarcar e suprir as necessidades do Sul.

Sobre esse cenário, Santos (2009a) descreve o pensamento moderno ocidental como "pensamento abissal". Ou seja, para o autor, a realidade ocidental se divide em duas realidades distintas. Uma realidade visível, amplamente aceita, e outra radicalmente excluída e invisibilizada como realidade possível - a realidade do Outro. Esta, então, eclipsada pela primeira, passa a inexistir como possibilidade outra, restando apenas, a realidade despótica e hegemônica. Da mesma forma, a própria concepção 
de que haja uma divisão entre ambas passa a se ocultar na sombra da impossibilidade.

Esta ideia, aplicada ao contexto brasileiro, pode tornar-se mais evidente quando pensamos que:

\begin{abstract}
Do ponto de vista do colonizador, é óbvio, os colonizados não tinham história antes de sua chegada à terra dos colonizados. Neste sentido, os colonizados deveriam agradecer aos colonizadores o fato de eles terem posto os colonizados na história. Da mesma forma, os colonizados não tinham cultura, antes da chegada dos colonizadores. A língua dos colonizados sempre foi camada de dialeto, e dialeto feio e pobre. Só a língua do colonizador é uma língua que tem possibilidades históricas, que tem flexibilidade para expressar a ciência, a técnica e as artes. A arte do colonizado é folclore, a arte do colonizador é cultura (FREIRE, 2003, p. 43-44).
\end{abstract}

Esta desvalorização, ou pior, esta inferiorização das culturas não eurocentradas é um sintoma preocupante de uma lógica necrófila. Quando vista como menor, quando desumanizada, a cultura dos povos tradicionais é aos poucos sufocada pela cultura ocidental e deixa de ser algo necessário para a construção de uma sociedade que tem como pilar constitutivo as culturas indígena e africana, como o é o caso do Brasil. Se por um lado podemos observar o aumento da necessidade de se discutir a diferença colonia|' epistêmica como "cúmplice do universalismo, sexismo e racismo" (BALLESTRIN, 2013, p. 104) - entre outras formas de silenciamento - do outro é notado que o "movimento de descobrimento e de revalorização das teorias e epistemologias do sul tem crescido nos últimos anos em diversas áreas e universidades do mundo" (BALLESTRIN, 2013, p. 104).

Nesse aspecto, a Educação pode ser entendida como um campo que foi e ainda é utilizado para semear as ideias e culturas dos colonizadores (FREIRE, 2011) e é dela que deve emergir o processo de decolonização. Para superar este dilema é necessário pensar, de acordo com Gomes (2006), em pedagogias da ausência e que emergem. São pedagogias pautadas nas demandas dos movimentos sociais, tendo como principal exemplo o

\footnotetext{
6 Termo cunhado por Mignolo para tratar do espaço onde a colonialidade do poder age. Trata-se de um "local ao mesmo tempo físico e imaginário" (2003, p. 10), onde histórias locais inventam os projetos globais. É o lugar onde estes projetos se interagem, são adotados ou rejeitados. Onde as histórias locais se confrontam.
} 
Movimento Negro. Trazer à tona esta discussão acerca dessas pedagogias é, sobretudo, uma forma de afirmação dos processos de desumanização pelo qual as classes marginalizadas passam. Para a autora, pautar a luta emancipatória como diretriz para o estabelecimento de uma educação preocupada com tais complexidades sociais, não configura uma utopia apenas, mas sim, uma realidade desesperada pela emancipação na produção de conhecimentos.

Mas como propor tal mudança de pensamento sem antes repensar as estruturas em que a Educação ocorre? Nas palavras de Gadotti (1995, p. 75), "para o fortalecimento das organizações contra-hegemônicas, a escola desempenha um papel fundamental, uma vez que é no seio da sociedade civil, no contexto do capitalismo, que se trava prioritariamente a luta política". Por isso, pensar as instituições tradicionais como mantenedoras da prática colonial, bem como repensar o papel político que a educação desempenha na formação cidadã, é fundamental para a redução das estruturas de dominação no contexto escolar.

Neste sentido, de acordo com Arroyo (2013), o currículo pode ser enxergado como um território de disputa. Os docentes que lutam por autonomia e pelo avanço na construção de novas tendências profissionais entram em desacordo com as orientações curriculares, que insistem em privilegiar o pensamento clássico sequenciado, castrador da criatividade tanto de alunos quanto de mestres. São as mesmas orientações curriculares que convencionam os selos reais da Metrópole.

Como não repensar a composição do currículo para a realização do giro decolonial7 também no contexto do conhecimento escolar? Os conceitos, visões de mundo e visões de como "ser no mundo" e "com o mundo" impressos no currículo escolar, não valorizam epistemologias outras, os costumes e pensamentos subalternos.

\footnotetext{
7 Proposição iniciada por Nelson Maldonado-Torres para se referir ao "movimento de resistência teórico prático, político e epistemológico, à lógica da modernidade/colonialidade" (BALLESTRIN, 2013, p. 105).
} 
Segundo Lopes (2004), as reformas educacionais propostas pelo governo objetivam mudanças em várias instâncias que tangem à educação, mas também guardam uma importância central. Essas reformas buscam a reafirmação ou a negação das práticas curriculares anteriores, e é através deste movimento que um governo busca a legitimação de seu projeto político-social. Dessa forma, podemos compreender que a não reformulação das bases curriculares para a valorização das culturas tradicionais guarda, como intencionalidade, um projeto de extinção dessas culturas.

Neste contexto, a superação das inquietações e angústias produzidas nas nações colonizadas não serão possíveis, senão, a partir da reformulação dos conceitos e conteúdos presentes no currículo. Isto não significa a total abolição dos currículos ou conhecimentos científicos. O que aqui se pretende reformular é a forma que estes são elencados, e a que narrativas se dão prioridade.

É possível então, compreender que currículo pode agir como um agente coagulante do diálogo entre ações docentes e a discussão da decolonialidade do ensino ao limitar a prática docente. Ou ainda, que este pode ser visto como um agente colonial, propriamente dito. Por esta razão, a produção de ações que não esteja em conformidade com o currículo, de nada valerá, se este ainda reverberar as práticas e competências cunhadas no ventre do pensamento moderno ocidental.

Uma maneira de compreender o exposto é a partir da apresentação dos conhecimentos científicos. Feita de forma totalmente conteudista, os conceitos e constructos acontecem através de uma exposição fora de contexto. Como consequência, uma única realidade é valorizada. Uma realidade que não é a do educando e que se propõem a explicar fenômenos que tem pouca ou nenhuma relevância para o cotidiano dentro e/ou fora de sala. É o que Adichi (2009) chama de história única. Uma só perspectiva sobre uma realidade e que gera conflitos e estereótipos sobre qualquer outra realidade diferente daquela única.

Segundo Arroyo (2013), são necessárias iniciativas que promovam a 
abertura dos currículos de educação básica para concepções de conhecimento menos fechadas, mais abertas à dúvida e às indagações que vêm do real, das vivências que os próprios educandos e educadores carregam, além de fazer das salas de aula laboratórios de diálogos entre conhecimentos (ARROYO, 2013, p. 37)

Algumas destas iniciativas podem ser percebidas, apesar dos abismos criados pelas práticas curriculares pautadas na transmissão de conhecimento. Destas, interessam a esta provocação, principalmente, as iniciativas que sejam capazes de abranger a temática étnico-racial. Uma delas é o decreto e sancionamento da Lei 10.639/03, que torna obrigatório o ensino sobre História e Cultura Afro-Brasileira. Assim, orienta para todo o currículo escolar o compromisso de trabalhar com a temática étnico-racial a partir dos conteúdos programáticos.

Esta lei tem como objetivo "o direito dos negros se reconhecerem na cultura nacional, expressarem visões de mundo próprias, manifestarem com autonomia, individual e coletiva, os seus pensamentos" (BRASIL, 2004, P.11). Ela propõe ainda reconhecer a importância do ressarcimento dos danos materiais, sociais e psicológicos sofridos pelos negros durante o período de escravidão; do resgate das contribuições histórias dos negros para a formação da sociedade brasileira; e do combate ao racismo, às discriminações que atravessam a escola.

Muito além de uma determinação hierarquicamente, imposta ao pavimento escolar, é esperado que esta lei se traduza em uma série de medidas, que articuladas, possam contemplar suas determinações. É compatível com essa ideia que as agências governamentais distribuam materiais didáticos adequados, invistam na formação de professores, valorizem projetos experiências educacionais autênticas.

Para dar sequência a esta provocação, desenvolvemos uma investigação sobre uma destas medidas esperadas: os livros didáticos. Tratase de uma análise qualitativa de livros didáticos para investigar de que maneira estes desenvolvem os temas relacionados à Lei 10.639/03. 
O material didático analisado faz parte do Plano Nacional do Livro Didático - PNLD. Estes livros integram uma iniciativa do Ministério da Educação para

avaliar e a disponibilizar obras didáticas, pedagógicas e literárias, entre outros materiais de apoio à prática educativa, de forma sistemática, regular e gratuita, às escolas públicas de educação básica das redes federal, estaduais, municipais e distrital e também às instituições de educação infantil comunitárias, confessionais ou filantrópicas sem fins lucrativos e conveniadas com o Poder Público (BRASIL, s. d.).

Sendo guias basilares que buscam compor as atividades educativas, os livros didáticos trazem detalhados os conhecimentos que integram os conteúdos mínimos. Estes conteúdos são estruturados pelos currículos e determinados pelas agências governamentais para fundamentar a prática educativa. Assim, para engendrar uma compreensão sobre a complexa organização do currículo, buscamos primeiramente questionar a relação dos livros com seus conteúdos.

\section{OS LIVROS DIDÁTICOS E O DIÁLOGO COM O ENSINO DAS RELAÇÕES ÉTNICO- RACIAIS}

Esta seção pretende apresentar a primeira etapa, que consiste na análise suleadora ${ }^{8}$ da pesquisa. Esta análise consistiu-se num estudo qualitativo de alguns livros didáticos de Química do Ensino Médio aprovados pelo PNLD 2018-2020 (Plano Nacional do Livro Didático). Estes livros são na verdade, manuais do professor recebidos para a escolha do material didático pelo docente. Mas antes de apresentar o estudo com os livros, é preciso dar um passo atrás para esclarecer o pano de fundo desta análise.

A preocupação com o estudo do referido material didático, surge como consequência da realização de leituras, além de vivências, acerca de referenciais teóricos da educação das relações étnico-raciais. Estas referências e vivências corroboraram para apontar a falta de recursos

\footnotetext{
8 Referência à nota 15 do livro Pedagogia da Esperança, onde Paulo Freire apresenta do neologismo como uma crítica ao termo nortear, usado como efeito de orientar algo (dar um norte). Como provocação decolonial, é esperado que este trabalho direcione as discussões para o Sul.
} 
materiais, principalmente livros didáticos, como uma problemática para a promoção da educação para igualdade.

Segundo Martins (2006, p.118), o livro didático possui uma "indiscutível importância" no âmbito escolar, como elemento de natureza historicamente constitutiva. Para a autora, sua importância

\begin{abstract}
é atestada, entre outros fatores, pelo debate em torno da sua função na democratização de saberes socialmente legitimados e relacionados a diferentes campos de conhecimento, pela polêmica acerca do seu papel como estruturador da atividade docente, pelos interesses econômicos em torno da sua produção e comercialização, e pelos investimentos de governos em programas de avaliação (MARTINS, 2006, p.118).
\end{abstract}

Assim, o livro didático torna-se um dos meios para efetuar a prática educativa, possuindo um multifacetado espectro de participação nessa prática. Mas, além disso, esse material é importante mediador da prática docente. Dessa forma, ao investigar os tipos de relação deste com a temática africana e afro-brasileira, também se investiga os tipos de relação que a sociedade e o Estado estabelecem com a temática em si.

Isso porque o livro didático é construído e reconstruído com base em determinadas tendências formativas, estabelecido, segundo Curry (1992), pelos responsáveis pela educação: no caso das instituições públicas, o Estado; no caso da educação privada, o mercado e instituições religiosas. E entendendo o racismo e o preconceito como marcos seculares estruturantes da sociedade brasileira (GOMES, 1996, 2005), a efetivação da Lei 10.639/03 pelo livro didático pode ser vista como um desafio na educação. Não só por questionar a relação do livro didático com seus promulgadores, mas da própria sociedade com suas bases violentamente excludentes.

Destrinchando, agora, as leituras que direcionam mais diretamente 0 estudo dos livros, estas se baseiam, principalmente, no texto da já citada lei, cujas palavras fortalecem e ecoam as pautas e demandas da população afro-brasileira - historicamente construídas, a partir das condições políticas e sociais resultantes da diáspora africana. Além da lei propriamente dita, nos fundamentamos também nas Diretrizes Curriculares Nacionais para a Educação das Relações Étnico-Raciais e para o Ensino de História e Cultura

Revista Exitus, Santarém/PA, Vol. 9, № 5, p. 47 - 76, Edição Especial 2019. 
Afro-Brasileira e Africana (BRASIL, 2004) e em autores como Munanga, (2012) e a já citada Gomes (1996, 2005, 2006, 2017).

A partir destes referenciais, torna-se evidente que a discussão do tema não se restringe apenas às disciplinas de cunho humanista ou artístico. Como trazido no artigo segundo da Lei 10.639/03, os "conteúdos referentes à História e Cultura Afro-Brasileira serão ministrados no âmbito de todo o currículo escolar, em especial nas áreas de Educação Artística e de Literatura e História Brasileiras" (BRASIL, 2003, grifo nosso). É importante salientar que as palavras "em especial" do mesmo trecho, apesar de atribuir à sentença um sentido ambíguo, privilegiando as disciplinas humanas, não excluem o dever de todas as disciplinas abordarem a temática étnico-racial - o que se torna claro com as palavras grifadas.

Assim, é necessário reafirmar esse compromisso de todo o currículo com o combate ao racismo através da relação de cada disciplina com as africanidades. Para isso, podemos citar algumas possibilidades que 0 currículo escolar pode adotar em sua extensão. Por exemplo, na Matemática, é possível perceber as diferentes formas de percepção dos processos operacionais e de contagem, bem como na criação de sistemas numerais funcionais e organizados (SILVA et al., 2017). Na Biologia, temos o conceito de "raça", que historicamente foi utilizado para dividir a humanidade entre "superiores" e "inferiores", mas já desmistificado pela própria biologia e pelo estudo da genética (GOMES, 2005). Na Literatura, entre várias, podemos destacar autores africanos contemporâneos, tais como Ana Paula Tavares, poetisa angolana, que inscreve, com vigor e sutileza, as mulheres negras e seus ritos de passagem na literatura; e Mia Couto, escritor moçambicano consagrado, que traz, através de fortes influências locais, elementos culturais diversos e relata os conflitos entre a sociedade Ocidental e as comunidades locais africanas. Outros exemplos mais poderiam ser dados, mas não vamos nos aprofundar nesta discussão, que será retomada mais adiante.

Encontramos nas Diretrizes Nacionais Curiculares para a Educação das Relações Étnico-Raciais (BRASIL, 2004), ou DCNERER, outra importante 
fundamentação para a nossa provocação. Segundo o documento, reconhecendo a pluralidade e diversidade étnica do país, as instituições escolares devem ter como referência alguns princípios para conduzir suas ações. Estes princípios têm como objetivo principal garantir aos indivíduos o direito irrestrito à educação e ampliação dos conhecimentos, sem postular a adesão a práticas contrárias, àquelas de seus grupos étnico-raciais de origem, bem como a negação das identidades próprias (BRASIL, 2004).

Retomando nossa análise, foram selecionados livros de três editoras aprovadas pelo PNLD 2018-2020. Cada editora conta com uma coleção de três volumes, um para cada série do ensino médio, totalizando nove livros. Em seguida, foi realizada a leitura completa do material, a fim de se encontrar ao menos uma menção ou representação textual da temática étnico-racial. Também foram supervisionadas as representações imagéticas, mas sem valor categórico. Com base nessas menções, traçamos categorias de análise para enquadrar as abordagens dos livros quanto às adequações que rumassem para o cumprimento da Lei 10.639/03, segundo as recomendações e apontamentos das DCNERER, pois entendemos tal documento como um forte percursor na construção de fundamentos para a decolonização dos livros didáticos.

As categorias apresentadas a seguir, têm como base algumas definições retiradas das próprias DCNERER. Salientamos que estas diretrizes não classificam os livros, esta classificação é fruto da ineditude do nosso trabalho. No entanto, estas categorias são inspiradas em trechos destas diretrizes, que orientam a (re)educação das relações étnico-raciais como dever da escola, e por consequência do(a) professor(a) e dos materiais escolhidos por este(a) professor(a).

QUADRO 1 - Definições das categorias de análise dos livros didáticos

\begin{tabular}{|c|c|}
\hline Categoria & Definição \\
\hline Abordagem efetiva da Lei $10.639 / 03$ & $\begin{array}{lrr}\text { Livros } & \text { "empenhados } & \text { na } \\
\text { valorização da história e cultura } \\
\text { dos afro-brasileiros e } & \text { dos } \\
\text { africanos, } & \text { assim } & \text { como } \\
\end{array}$ \\
\hline
\end{tabular}

Revista Exitus, Santarém/PA, Vol. 9, № 5, p. 47 - 76, Edição Especial 2019. 


\begin{tabular}{|c|c|}
\hline & $\begin{array}{l}\text { comprometidos com a de } \\
\text { educação de relações étnico- } \\
\text { raciais positivas, a que tais } \\
\text { conteúdos devem conduzir" } \\
\text { (BRASIL, 2004, p. 9) }\end{array}$ \\
\hline Abordagem parcial da Lei 10.639/03 & $\begin{array}{l}\text { Os livros didáticos que trazem a } \\
\text { discussão de "questões tão } \\
\text { complexas, muito pouco tratadas } \\
\text { maneira resumida, [ou] } \\
\text { incompleta" (BRASIL, 2004, p.18), } \\
\text { que resulta em um modo } \\
\text { "reduzido de tratar a contribuição } \\
\text { dos africanos escravizados e de } \\
\text { seus descendentes"(BRASIL, 2004, } \\
\text { p. 18) }\end{array}$ \\
\hline Ausência de abordagem da Lei 10.639/03 & $\begin{array}{l}\text { Os livros que reproduzem } \\
\text { pressupostos da cultura nacional } \\
\text { de um "imaginário étnico-racial } \\
\text { que privilegia a brancura e } \\
\text { valoriza principalmente as raízes } \\
\text { européias da sua cultura" (BRASIL, } \\
\text { 2004, p. 14) }\end{array}$ \\
\hline
\end{tabular}

Fonte: elaboração própria

A seguir, procuramos explorar um pouco mais as definições apresentadas no Quadro 1. Para isso, foram utilizados fragmentos retirados do próprio material analisado para exemplificar cada definição, bem como para basear nossa discussão dos resultados.

\section{Abordagem efetiva da Lei 10.639/03}

Esta categoria engloba as possibilidades temáticas elencadas pelo material que permitem que o professor possa laborar os elementos afrocentrados de maneira clara e em diálogo com os conhecimentos científicos do livro. Dessa forma, fica possibilitado que os elementos étnicoraciais sejam trabalhados não como simples exemplo ou complemento curricular, mas como conteúdo tão significativo quanto o conteúdo curricular.

Além disso, por estar presente de forma efetiva no corpo do texto do material didático, o conteúdo afrocentrado torna-se parte do repertório de estudo dos alunos. Isto familiariza e aproxima a temática em questão da possibilidade de leitura, auxiliando no processo da dinâmica docente. 
Como exemplo, é trabalhada a compreensão das influências culturais indígenas, africanas e portuguesas na culinária nacional. O tema é abordado com o conceito de "transformações químicas", um dos tópicos iniciais do $1^{\circ}$ ano do Ensino Médio. No Currículo Mínimo do Rio de Janeiro (2012) é trabalhado no eixo temático "Química, Tecnologia, Sociedade e Ambiente" do primeiro bimestre.

Imagem 1: (a) Exemplo de abordagem satisfatória. (b) continuação do extrato

(a)

(b)

Influências na alim
A cozinha brasileira tem por base a cozinha
portuguesa, com outras duas grandes influências:
a indígena e a africana. [...] O primeiro depoimento
sobre a alimentação indígena é a carta de Pero Vaz
de Caminha, o escrivão da frota de Cabral [...].
[...]
O índio não conhecia a cana-de-açúcar, que só
veio com a colonização, mas usava o mel de abe-
lhas, que existia em abundância em nossas matas.
Com o mel, o índio também fazia bebidas. O sal era
retirado da vegetação e não da água do mar. Os ín-
dios queimavam os troncos das palmeiras até se
transformarem em cinzas, que então eram fervi-
das para obter o sal, de cor parda. Em 1549, o pa-
dre Manoel da Nóbrega, guia dos primeiros jesuítas
que vieram ao Brasil, afirmava que "o mantimento
comum da terra é uma raiz de pau que chamam
mandioca". Caminha cita, erroneamente, o inhame
como alimento nativo. Tratava-se, na verdade, da
nossa mandioca. O inhame foi trazido ao Brasil só
mais tarde, pelos africanos.
[...] A cozinha brasileira sofreu uma série de in-
fluências, mas a culinária indígena não se dissolveu
20

- [...] O coqueiro e o leite de coco, aparentemente tão brasileiros, também vieram do continente africano, bem como o azeite de dendê. A palmeira do dendê foi cultivada ao redor da cidade de Salvador, o maior centro demográfico da época, onde a presença africana tornou-se marcante. [...] Os negros trouxeram para o país a pimenta africana, cujo nome localizava a origem, Malagueta. [...] O negro criou

na aculturação, como a culinária negra, hoje dificilmente legítima. A comida indígena permaneceu relativamente fiel aos modelos quinhentistas e aos padrões da própria elaboração das farinhas, assados de carne e peixe, bebidas de frutas. [...] os portugueses introduziram hábitos que marcaram definitivamente nosso paladar: valorizaram o uso do sal e revelaram o açúcar aos africanos e índios do Brasil. [...] Os nativos e os africanos não usavam óleos vegetais e muito menos gorduras animais para preparar os alimentos. Não conheciam a fritura. Outra revelação portuguesa.

[...] Os negros faziam farinha, já conhecida pelos tupis brasileiros. Comiam o milho sempre cozido, em forma de papa, angu ou fervido com leite de vaca, em preparo semelhante ao atual mungunzá. A banana foi herança africana no século XVI e tornou-se inseparável das plantações brasileiras, cercando as casas dos povoados e as ocas das malocas indígenas, e decorando a paisagem com o lento agitar de suas folhas. [...] A banana foi a maior contribuição africana para a alimentação do Brasil, em quantidade, distribuição e consumo.

um jeito de fazer render a pouca comida que recebia: inventou o pirão escaldado chamado massapê, feito com farinha de mandioca e água fervente, acrescido de pimenta-malagueta. O massapê ainda é usado em nosso meio rural. [...]

Fonte: RECINE, E.; RADAELLI. P. Alimentação e cultura.

Biblioteca Virtual em Saúde, Ministério da Saúde. Disponivel em: <http://bvsms.saude.gov.br/bvs/publicacoes/alimentacao cultura.pdf>. Acesso em: out. 2015

Perguntas sobre o tekto Responda em seu caderno

1 Que evidências de transformação química aparecem no texto?

2 Esboce um mapa-múndi e indique nele a origem de produtos citados no texto que influenciaram a nossa culinária.

3 Com base nas informações do texto e do seu conhecimento pessoal, descreva o que você entende por aculturação.

Fonte: Volume 2 da Editora B.

Além dos elementos culturais presentes na Imagem 1, aparecem também algumas questões que complementam a discussão geral do texto. A primeira justamente indica a contextualização do tema exposto e o conteúdo curricular ao solicitar a busca pelos traços do conteúdo no texto.

Revista Exitus, Santarém/PA, Vol. 9, № 5, p. 47 - 76, Edição Especial 2019. 
As demais se referem a conhecimentos para além dos domínios da química, mas igualmente correlatos à discussão.

Através da clara explicitação das informações, o trabalho docente pode ser conduzido de maneira eficaz e tornando o conhecimento em questão inteligível, sem necessidade de um amplo aprofundamento teórico. Dessa forma, o conteúdo pode ser abordado de forma contextualizada, promovendo o respeito às diferenças e a difusão da diversidade a partir da culinária.

\section{Abordagem parcial da Lei 10.639/03}

Diferente do primeiro tipo de abordagem, esta representa as construções textuais que utilizam a temática étnico-racial como simples exemplo para o conteúdo programático. Além disso, nesta categoria, o material não valoriza a cultura e história africana e/ou afro-brasileira, pois se caracteriza como uma aparição pouco profunda e esclarecida do tema. Ou ainda, por exemplos que possam gerar ou agravar estereótipos que permeiam a compreensão das relações étnico-raciais.

Imagem 2: Exemplo de abordagem não satisfatória.

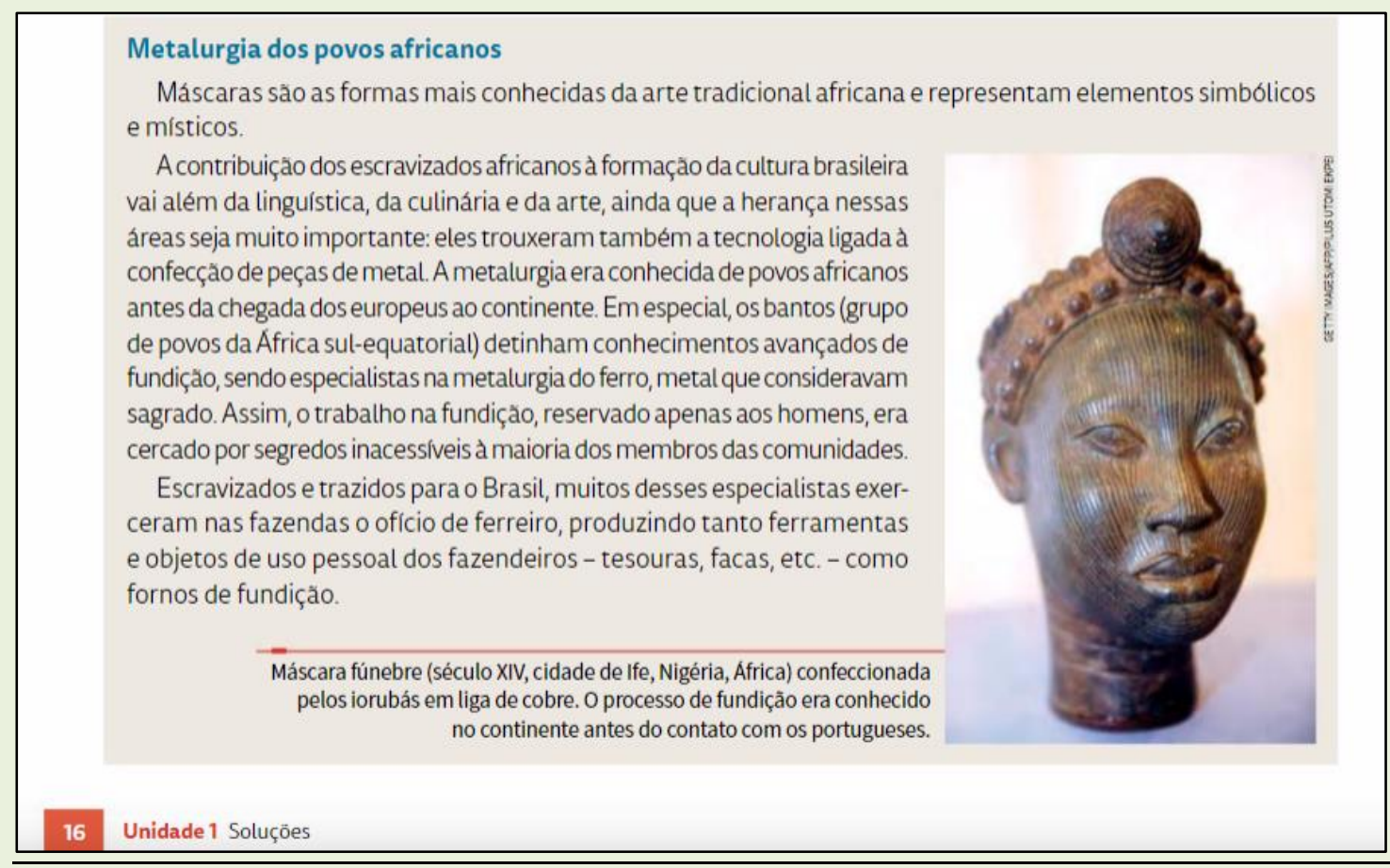

Fonte: Volume 2 da Editora C. 
Neste caso, é possível observar um exemplo apresentado no texto sobre "Soluções Sólidas", no capítulo "Soluções e dispersões coloidais: aspectos básicos". Apesar de trazer a metalurgia como sabedoria a africana, no contexto das ligas metálicas como soluções sólidas, o exemplo não é aprofundado nem muito bem esclarecido. Quais são os "conhecimentos avançados de fundição"? Como produziam suas ligas metálicas? Por que o ferro era considerado sagrado?

Tendo em vista que o texto da abordagem não responde a algumas considerações sobre o exemplo mostrado, é possível perceber a Imagem 2 como uma alegoria do texto principal, cabendo apenas a título de curiosidade. Assim, o conhecimento ancestral por trás do exemplo fica em segundo plano, podendo não ser enfatizado. Dessa forma, para maior aprofundamento tanto docente quanto discente é necessário recorrer a outras ferramentas.

O que é necessário reforçar, nesta circunstância, é que não se pretende atacar ou criticar a possibilidade de investigação que possa vir a ser feita pelos interlocutores do processo de ensino-aprendizagem. Pelo contrário, a investigação é necessária para a apropriação e manutenção do vigor do ato de conhecer. No entanto, quando consideramos a realidade do ensino público, sobretudo, nas periferias urbanas, a escola tem o compromisso com a educação de qualidade e que leve não só o conhecimento cobrado pelos exames estaduais e federais, mas também o conhecimento historicamente negado às gerações que possuem descendência dos povos tradicionais.

Ausência de abordagem da Lei 10.639/03

Por último, de maneira bem sucinta, esta categoria é referente aos livros didáticos, que no desenrolar de seu texto, não trabalha os conteúdos discutidos pela Lei 10.639/03 em diálogo com os conhecimentos científicos do livro didático. 


\section{Imagem 3: Exemplo que não aborda}

\section{Alótropos do carbono}

O elemento carbono possui duas formas alotrópicas naturais: carbono grafita, $C_{n}$, e carbono diamante, $C_{n}$, sendo $n$ um número muito grande e indeterminado, e também algumas formas alotrópicas sintéticas. Os alótropos naturais do carbono diferem entre si quanto ao arranjo cristalino dos átomos no espaço.

A tabela a seguir traz algumas informações desses alótropos.

\begin{tabular}{|c|}
\hline Alótropos do carbono \\
\hline Características e propriedades dos alótropos \\
\hline Grafita, $C_{n}$ \\
\hline $\begin{array}{l}\text { É um sólido cinza-escuro, baixa dureza, conduz eletricidade e calor. Possui um arranjo } \\
\text { cristalino mais estável, portanto menos energético. Os cristais de diamante tendem } \\
\text { a se transformar em grafita espontaneamente, embora isso leve milhões de anos para } \\
\text { ocorrer. }\end{array}$ \\
\hline $\begin{array}{l}\text { Possui densidade }=2,26 \mathrm{~g} / \mathrm{cm}^{3} ; \text { temperatura de fusão }=3550^{\circ} \mathrm{C} \text { e temperatura de } \\
\text { ebulição }=4200^{\circ} \mathrm{C}\end{array}$ \\
\hline $\begin{array}{l}\text { Na estrutura cristalina os átomos de carbono formam hexágonos no espaço. As placas } \\
\text { de hexágonos são mantidas juntas por forças de atração mútua. }\end{array}$ \\
\hline
\end{tabular}

\section{Diamante, $\mathrm{C}_{n}$}

Sólido incolor, elevada dureza, não conduz eletricidade nem calor.

É formado na natureza nas camadas mais internas da Terra, em condições de alta pressão e temperatura. É expelido para a crosta terrestre devido aos movimentos geológicos naturais. Sabendo disso, os cientistas começaram a fabricar diamantes sintéticos, modificando a estrutura cristalina da grafita por meio de aparelhos que produzem pressões e temperaturas altíssimas. Hoje esse processo está tão aperfeiçoado que os diamantes sintéticos, além de serem usados em ponta de brocas (pela elevada dureza), já podem ser lapidados para a fabricação de joias.

Possui densidade $=3,51 \mathrm{~g} / \mathrm{cm}^{3}$; temperatura de fusão $=3550^{\circ} \mathrm{C}$ e temperatura de ebulição $=4200^{\circ} \mathrm{C}$

\section{Estrutura cristalina}

Na estrutura cristalina cada átomo de carbono acha-se ligado tetraedricamente a quatro outros átomos de carbono.

\section{Buckminsterfulereno, $\mathrm{C}_{60}$}

Os fulerenos foram descobertos na década de 1970 por cientistas da Universidade de Sussex, ศิo Reino Unido, durante investigações sobre moléculas existentes na poeira interestelar de estrelas vermelhas gigantes. Na Terra, a substância é obtida pela vaporização do carbono grafita em atmosfera de gás hélio (atmosfera inerte) e possui densidade inferior à das outras formas alotrópicas do carbono $\left(1,65 \mathrm{~g} / \mathrm{cm}^{3}\right)$. A densidade relativamente baixa do $C_{60}$ resulta do fato de haver muito espaço vazio em sua estrutura e entre as esferas.

O nome buckminsterfulereno é uma homenagem ao arquiteto norte-americano Buckminster Fuller, criador da estrutura geodésica.

A estrutura cristalina mostra a forma mais comum que contém 60 átomos de carbono, $\mathrm{C}_{60}$, dispostos de maneira a parecer uma minúscula bola de futebol, com 60 vérticese 32 faces compostas de 12 pentágonos e de 20 hexágonos. Outras variedades alotrópicas sintéticas do carbono são os chamados nanotubos de carbono.

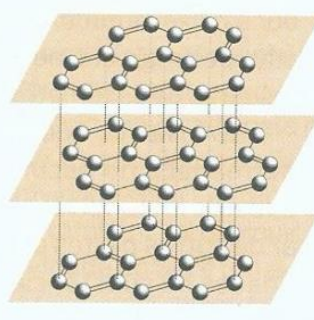

Fonte: PERRY, Robert H.; GREEN, Don W. Perry's Chemical Engineer's Handbook. $6^{\text {th }}$ ed. Kansas: McGraw-Hill, 1984. (Chemical Engineering Series).

126

Capítulo 5

Fonte: Volume 1 da Editora A

Revista Exitus, Santarém/PA, Vol. 9, № 5, p. 47 - 76, Edição Especial 2019. 
Na Imagem 3, temos o conceito de "alotropia", presente no capítulo "Notações Químicas" do livro do qual foi extraído. Neste trecho, podemos ver claramente que o tema é abordado de maneira não articulada com os princípios previstos pela Lei 10.639/03. Dessa forma, o conhecimento científico se mostra distante do diálogo com as africanidades, alimentando seu antecedente de mero enunciador de saberes hegemônicos.

Podemos ainda ampliar nossa crítica ao contexto apresentado na Imagem 3 e demonstrar que é possível realizar uma outra abordagem dos conceitos químicos em questão, trazemos como exemplo um trabalho em que em que é possível observar o diálogo com as africanidades com o conhecimento científico. No trabalho de Pinheiro e Silva (2010), que visa analisar a produção de conteúdos digitais por estudantes de licenciatura, é apresentada uma proposta de articulação dos conhecimentos científicos da Imagem 3 com o contexto de exploração de diamante no continente africano. Entretanto, sobre isto é importante fazer a seguinte ressalva: esta abordagem deve servir como forma de denúncia das consequêcias sociais do extrativismo mineral no continente africano. O que queremos dizer é que neste aspecto, este tipo de implementação da Lei 10.639/03 pode alimentar, como comentado, os estereótipos de África desumanizada e largada à própria sorte. Para evitar isso, esta proposta poderia ser desenvolvida como atividade interdisciplinar, para valorizar o debate entre as áreas do conhecimento.

Após estas considerações sobre cada categoria desta etapa de análise, devemos retomar a discussão do contexto geral da análise em si. Como o objetivo final deste trabalho não é apenas investigar as dificuldades de efetivação da lei supracitada, o desfecho desta provocação não favorece a leitura individual dos números e suas devidas inferência, mas sim, a interpretação no contexto global da análise.

Nesse aspecto, é possível traçar um panorama geral, diga-se de passagem, preocupante. Mesmo após dezesseis anos de aprovação da lei, a maior parte dos livros de Químicadas de editoras analisadas, que compõem a lista doPNLD 2018-2020 e que deveriam seguir em conformidade

Revista Exitus, Santarém/PA, Vol. 9, № 5, p. 47 - 76, Edição Especial 2019. 
com as DCNERER, faz uma abordagem não satisfatórias sobre a cultura e histórias africanas e afro-brasileiras, ou não aborda o tema.

Quando presente no texto verbal, nosso objeto de interesse foi apresentado sob a abordagem não satisfatória, majoritariamente. Assim, observamos que o material didático analisado reforça um entendimento de que o conhecimento científico é construído apenas sobre pilares europeus, descartando outras epistemologias como integrantes de um sistema dinâmico de produção de saberes humanos. É, justamente, na desconstrução deste entendimento que as DCNERER são estruturadas.

Dessa forma, os livros apresentam um caráter essencialmente dicotômico de anúncio e de denúncia. Eles anunciam a perpetuação dos processos de dominação do colonizador; e denunciam a necessidade da descolonização dos saberes. De um lado exibe-se uma Ciência (Química) europeia, vitoriosa frente à corrida epistêmica global. E do outro, oculta-se o conhecimento ancestral, vencido, subjugado pelo saber do opressor.

Chegamos, dessa forma, a um impasse. O que podemos perceber é que a principal ferramenta didática do professor de ciências, em especial o de Química, é um manual de conhecimento que, grosso modo, não aborda e/ou superficializa a discussão da Lei citada em sala de aula. Seria o livro didático uma das máscaras de Flandres, que faz perder o vício do português aos aculturados, por thes silenciar ${ }^{9}$ no ambiente escolar? Seria o didático um óbice colonial da prática docente em sala de aula?

Quando tomamos novamente as Diretrizes para Educação das Relações Étnico-Raciais, percebemos que o material didático ainda resiste em seguir as recomendações de seus princípios de ação, citados anteriormente. Uma forma de combater este impasse é com o investimento e criação de materiais de apoio para o professor que fomentem a discussão de maneira mais ampla e aprofundada. Estas, entre outras, é uma das maiores preocupações deste trabalho.

\footnotetext{
9 Paráfrase da passagem do conto Pai contra Mãe de Machado de Assis "A máscara [de Flandres] fazia perder o vício da embriagues aos escravos, por lhes tapar a boca". (MARTINS, 2007, p. 55).
} 
No entanto, observa-se que este esforço vem sendo limitado por vários agentes, como a formação docente e as políticas escolares - que seguem as recomendações curriculares governamentais (ARROYO, 2013). E mesmo com a existência de diretrizes curriculares e pareceres sobre a inserção das histórias e culturas afro-brasileiras, como visto pela análise desta seção, pouco avanço foi feito.

Assim sendo, como encaminhamento final desta provocação, apresentaremos uma proposta curricular decolonial baseada na efetivação da Lei 10.639/03. A hipótese que se pretende sustentar, dessa forma, é que a partir de um currículo fundamentalmente decolonizador, numa perspectiva afrocentrada, seja possível reiterar as suposições até agora levantadas.

\section{PROPOSTA CURRICULAR PARA A REFLEXÃO DECOLONIAL}

Como etapa final desta provocação, são trazidas algumas propostas para a decolonização do currículo de Química. Para isso, levantaremos algumas possibilidades de abordagem do conteúdo de química, direcionadas sob a perspectiva da Lei 10.639/03 e baseadas no Currículo Mínimo de Química do Estado do Rio de Janeiro (SEEDUC, 2012).

O currículo mínimo traça as diretrizes estaduais para a orientação das instituições públicas de ensino básico na construção autônoma de seus currículos (SEEDUC, 2012). Tem ainda a intenção de homogeneizar a rede de ensino público através do fornecimento dos meios básicos para contribuir com as diversas necessidades das instituições, ao elencar os conhecimentos das áreas por seriação e por bimestre. Desse modo, o documento tem a preocupação com a contribuição para a formação profissional, acadêmica e cidadã dos educandos.

No entanto, ao confrontarmos o currículo com a discussão dos apontamentos dos livros didáticos, percebemos que existe uma lacuna entre a implementação da Lei 10.639/03 e o Currículo Mínimo. A esta lacuna que pretendemos mirar com a proposta decolonial. Esta proposta é apresentada da seguinte maneira: traçaremos um paralelo entre o conteúdo mínimo e o 
conteúdo que emerge a partir da discussão da Lei 10.639/03, fazendo comentários e apontamentos sobre cada um.

QUADRO 2 - Proposta Decolonial de Currículo Étnico-racial

\begin{tabular}{|c|c|c|}
\hline $\begin{array}{c}\text { Ano (EM)/ } \\
\text { Bimestre }\end{array}$ & $\begin{array}{c}\text { Conteúdo Mínimo (Eixo } \\
\text { Temático) }\end{array}$ & Conteúdo étnico-racial \\
\hline $1^{\circ} / 1^{\circ}$ & $\begin{array}{c}\text { Química, Tecnologia, } \\
\text { Sociedade e Ambiente }\end{array}$ & O Ferro e o Ferreiro \\
\hline $2^{\circ} / 1^{\circ}$ & $\begin{array}{c}\text { Comportamento químico } \\
\text { das substâncias - Sais e } \\
\text { óxidos }\end{array}$ & Cerâmicas \\
\hline $2^{\circ} / 3^{\circ}$ & $\begin{array}{r}\text { Misturas } \\
\text { multicomponentes }\end{array}$ & $\begin{array}{c}\text { O mundo é feito de } \\
\text { misturas }\end{array}$ \\
\hline $3^{\circ} / 3^{\circ}$ & $\begin{array}{r}\text { Funções orgânicas: } \\
\text { grupos funcionais } \\
\text { (álcool) }\end{array}$ & \begin{tabular}{c} 
História da Cachaça \\
\hline $3^{\circ} / 4^{\circ}$
\end{tabular} \\
\hline $\begin{array}{c}\text { Química Orgânica - } \\
\text { Biomoléculas e Polímeros }\end{array}$ & $\begin{array}{c}\text { Bioquímica Afro- } \\
\text { brasileira }\end{array}$ \\
\hline
\end{tabular}

Fonte: Elaboração própria.

Apresentada a proposta, podemos fazer algumas considerações pontuais e gerais acerca do exposto. Sobre as considerações pontuais, é possível descrever resumidamente a ligação de cada conteúdo étnicoracial com o conteúdo mínimo associado:

$1^{\circ}$ ano

No primeiro bimestre do primeiro ano, pensou-se na exposição e estudo dos conhecimentos ancestrais dos ferreiros africanos, mais precisamente de Angola, para trabalhar os conhecimentos iniciais apresentados na disciplina de Química. De acordo com Hampaté Bâ (2010), o ofício do ferreiro demanda não só o conhecimento sobre a forja, mas também os conhecimentos que conectam sua atividade com a própria natureza primordial do mundo. Nesse aspecto, o tema do ferreiro com outros conceitos da química (PINHEIRO; SILVA, 2010), no entanto, optamos por descrevê-lo no primeiro semestre devido à possibilidade de construção da importância da tradição oral para a cosmogonia africana, no contexto do ofício do ferreiro. Além disso, diz o autor: "Os conhecimentos do ferreiro devem abranger um vasto setor da vida [...] Não apenas sabe tudo o que 
diz respeito aos metais, como também conhece perfeitamente a classificação das plantas e suas propriedades" (HAMPATÉ BÂ, 2010).

Ainda nesse bimestre, os conceitos referentes à "constituição da matéria" seriam abordados através das discussões a respeito dos elementos que circundam a alotropia do carbono - como trazido num dos exemplos de abordagens da seção anterior deste trabalho. Assim, trabalhar as propriedades da matéria a partir dos alótropos de carbono, como carvão ou grafite e diamante pode ser um "pontapé" inicial para se discutir os conflitos de poder relacionados ao extrativismo destes materiais no continente africano.

$2^{\circ}$ ano

No primeiro bimestre do segundo ano, pensou-se no ensino do uso de cerâmicas em diferentes culturas, tanto na África, por exemplo, com os Bawoyo (SERRANO, 1993) quanto no Brasil, por exemplo, com os Marajoaras (SCHAAN, 2009) - em diálogo com a Lei 11.645/0810. O processo de pintura destas cerâmicas é geralmente feito utilizando corantes feitos de sais e óxidos (UFRGS, s. d.), devido ao alto ponto de fusão.

No terceiro bimestre, a proposta é expor os conteúdos que englobam as misturas e soluções, a partir da culinária afro-brasileira (SANTOS et al., 2013). Vale lembrar que esse segmento da herança afro-brasileira também foi citado, na seção sobre livros didáticos, como possibilidade para abordar transformações químicas para o primeiro ano.

$3^{\circ}$ ano

No terceiro bimestre o terceiro ano, temos a apresentação das funções orgânicas, mais precisamente a dos "álcoois", a partir do plantio, extração da cana-de-açúcar e todo o processo de produção da cachaça

\footnotetext{
10 "Altera a Lei no 9.394, de 20 de dezembro de 1996, modificada pela Lei no 10.639, de 9 de janeiro de 2003, que estabelece as diretrizes e bases da educação nacional, para incluir no currículo oficial da rede de ensino a obrigatoriedade da temática 'História e Cultura AfroBrasileira e Indígena'"' (BRASIL, 2008).
}

Revista Exitus, Santarém/PA, Vol. 9, № 5, p. 47 - 76, Edição Especial 2019. 
- que também gera outras substâncias orgânicas. Já no quarto bimestre, optou-se por apresentar o respectivo conteúdo mínimo, a partir dos conhecimentos sobre alguns dos principais produtos naturais da cultura afrobrasileira: o dendê (SILVA et al., 2017), o café (BASTOS et al., 2017) e a nozde-cola (MOREIRA et al., 2011). Estes produtos são significativamente constituídos de substâncias presentes nos conteúdos de bioquímica.

Prosseguindo com as considerações gerais, é necessário ressaltar que a proposta foi estruturada com base no currículo mínimo levando-se em consideração que entendemos que, apesar das críticas realizadas, tal proposta não seria viável dentro dos parâmetros nacionais (BRASIL, 2004) para a educação se houvesse grandes contradições entre o currículo decolonizado e o currículo vigente. No que tange o cumprimento da Lei 10.639/03, é notável a grande resistência docente em tratar da cultura afrobrasileira (BENITE et al., 2012). Assim, com a apresentação de uma proposta completamente às avessas do currículo em vigor, seria esperado o reforço a essas resistências que assolam os dezesseis anos de assinatura da referida lei.

Por fim, é observado que muitos conteúdos não foram contemplados com a proposição realizada. Isso se deveu em parte pela complexidade de inculcar os dois currículos, visto que, como dito anteriormente, uma das dificuldades encontradas na implementação da Lei 10.639/03 é a falta de material didático que aborde a temática africana (MARQUEZ, 2016).

\section{CONCLUSÃO}

Em vista dos argumentos apresentados, podemos inferir que o currículo de Química preserva a identidade colonial da educação no Brasil, a partir dos aspectos combatidos pela decolonialidade. Sendo assim, entender o currículo como um território em disputa a ser explorado em suas particularidades é o primeiro passo para ascender para uma política curricular democrática e libertadora (FREIRE, 2011).

A colonialidade é ainda, denunciada/anunciada em nossa leitura e interpretação da análise realizada com os livros didáticos, que carregam em si as diretrizes do currículo que tendem a privilegiar a narrativa europeia. Os

Revista Exitus, Santarém/PA, Vol. 9, № 5, p. 47 - 76, Edição Especial 2019. 
livros que deveriam embasar a prática docente para a promoção da igualdade de formação das identidades individuais e coletivas, pautadas nas relações étnico-raciais previstas pela legislação, não fazem isso. Poucos são os casos em que a cultura e conhecimentos dos povos tradicionais assumem nos livros a devida visibilidade pela construção da cultura e história nacionais, sem reforçar imagens depreciativas ou difamatórias.

Neste contexto, reforçamos a ideia de que o ensino de Química possa agir como mais um manifesto da colonialidade criticada ou como agente decolonial. Como manifestação das marcas coloniais, o ensino de Química se caracteriza por privilegiar as contribuições e pensamentos eurocêntricos que construíram o mundo. Pensamentos que subjugam as comunidades tradicionais, negam gerações e gerações de conhecimento e enriquecem os colonos.

Já como agente decolonial, o ensino de Química pode valorizar um argumento novo, um argumento que refuta as atitudes autoritárias e impositivas construídas ao longo de séculos de exploração. Atitudes que nutriram a busca e domínio de materiais e suas propriedades, valorizando as culturas abaladas pela propagação de suas ideias racionalistas e cartesianas.

Sobre estas críticas é importante salientar a necessidade de vinculação entre utopia, discurso e ação, que segundo Freire (2016), são necessários para o estabelecimento de uma educação que não prime pelo autoritarismo ou pela postura licenciosa dos escravos da liberdade. Da mesma forma que é tirana a imposição do poder através da força, também o culto despudoradamente seduzido pelo sonho da liberdade é um ato de tirania.

Por que, então, pensar um currículo negro? Porque a partir da decolonização do currículo podemos enxergar uma possibilidade didática para a modificação do material didático em prol da valorização de conhecimentos que podem ser narrados também a contrapelo (BENJAMIN, 1985). Porque apesar das iniciativas como a homologação da Lei 10.639/03, com a obrigatoriedade do ensino das africanidades, e a inclusão do feriado

Revista Exitus, Santarém/PA, Vol. 9, № 5, p. 47 - 76, Edição Especial 2019. 
da Consciência Negra no calendário escolar para o fomento da valorização da cultura africana, poucas iniciativas públicas são criadas para, de fato, combaterem a discriminação racial e os altos índices de desigualdade referentes à população negra (MUNANGA, 2004). Além disso, poucas iniciativas têm sido feitas para manter os avanços já conquistados. Isso pode ser visto pelo baixo índice de impacto da Lei 10.639/03 em seus 16 anos de vigência.

Neste aspecto, consideramos ainda a formação continuada como um caminho possível para a implementação da Lei 10.639/03 e da reflexão sobre os desdobramentos da questão discutida (BENITE et al., 2012). O preparo e aproximação dos profissionais da educação com o ensino das relações étnico-raciais para o respeito às diferenças e admiração de nossas igualdades ainda configura um importante mecanismo de combate ao preconceito no ambiente escolar.

Diante de todas as adversidades aqui destacadas, ainda enxergamos no cenário da educação nacional um lampejo de esperança. Apesar de toda a estrutura colonial que persiste em assolar os livros didáticos e o currículo de Química, nos cabe lutar por uma sociedade menos desigual. Que esta esperança no novo movimente e se transforme em ação para a mudança. Ação do verbo esperançar.

\section{REFERÊNCIAS}

ADICHIE, C. N. O perigo da história única. TED. 2009. Disponível em: <https://www.ted.com/talks/chimamanda_adichie_the_danger_of_a_single_ story/transcript?language=pt\#t-16445>. Acesso em: 07 de dez. 2018.

ARROYO, M. G. Currículo, território em disputa. Petrópolis: Vozes, 2013.

BALLESTRIN, L. América Latina e o giro decolonial. Revista Brasileira de Ciência Política, n¹1. Brasília, maio - agosto, p. 89-117, 2013.

BASTOS, M. A.; AMAURO, N. Q.; BENITE, A. M. C. A química do café e a lei 10.639/03: uma atividade prática de extração da cafeína a partir de produtos naturais. Revista da Associação Brasileira de Pesquisadores/as Negros/as (ABPN), [S.I.], v. 9, n. 22, p. 312-331, jun, 2017.

BENITE, A. M. C.; SOUZA, E. P. L.; ALVINO, A. C. B.; SANTOS, M. A. Cultura Africana e Ensino de Química: estudos sobre a configuração da identidade 
docente. In: XVI Encontro Nacional de Ensino de Química (XVI ENEQ) e X Encontro de Educação Química da Bahia (X EDUQUI) Salvador, BA, Brasil - 17 a 20 de julho de 2012.

BENJAMIN, W. Magia e técnica, arte e política: ensaios sobre literatura e história da cultura. São Paulo: Brasiliense, 1985.

BRASIL. Lei 10.639/2003, de 9 de janeiro de 2003. Diário Oficial da União, de janeiro de 2003.

BRASIL. Lei 11.645/2008, de 10 de março de 2008. Diário Oficial da União, de março de 2008.

BRASIL. Ministério da Educação. Conselho Nacional de Educação. Diretrizes Curriculares Nacionais para a Educação das Relações Étnico-Raciais e para o Ensino de História e Cultura Afro-Brasileira e Africana. Relatora: Petronilha Beatriz Gonçalves. Ministério da Educação. Brasília, 2004.

BRASIL. PNLD. Disponível em: <http://portal.mec.gov.br/component/content/article?id=12391:pnld>. Acesso em 05 de janeiro de 2018.

COUTO, M. Cada homem é uma raça. São Paulo: Companhia das Letras, 2013.

CURRY, C. R. J. O público e o privado na Educação Brasileira contemporânea: posições e tendências. Cadernos de Pesquisa, São Paulo, n. 81, p. 33-44, maio, 1992.

DUSSEL, E. Europa, modernidad y eurocentrismo. In: LANDER, E. (coord.). La colonialidaddel saber: eurocentrismo y ciencias sociales, perspectivas latinoamericanas. Buenos Aires: Clacso, 2000.

FANON, F. Os condenados da terra. Rio de Janeiro: Civilização Brasileira, 1968.

FREIRE, P; GUIMARÃES, S. A África ensinando a gente: Angola, Guiné-Bissau, São Tomé e Príncipe. São Paulo: Paz e Terra, 2003.

FREIRE, P. Pedagogia do Oprimido. 50. ed. Rio de Janeiro: Paz e Terra, 2011.

FREIRE, P. Pedagogia da Indignação: cartas pedagógicas e outros escritos. (Organização e participação de Ana Maria Araújo Freire). 3. ed. São Paulo: Paz e Terra, 2016.

GADOTTI, M. Concepção dialética da educação: um estudo introdutório. São Paulo: Editora Cortez, 1995.

GOMES, N. L. Educação, raça e gênero: relações imersas na alteridade. Cadernos Pagu, Campinas, nº 6-7, p. 67-82, 1996. 
GOMES, N. L. Alguns termos e conceitos presentes no debate sobre relações raciais no Brasil: uma breve discussão. In: BRASIL. Educação Anti-racista: caminhos abertos pela Lei federal $n^{\circ}$ 10.639/03. Brasília, MEC, Secretaria de educação continuada e alfabetização e diversidade, p. 39-62, 2005.

GOMES, N. L. O negro no Brasil de hoje. São Paulo: Global, 2006.

GOMES, N. L. O movimento negro educador. Petrópolis: Vozes, 2017.

HAMPATÉ BÂ, A. Tradição viva. In: História geral da África I. ZERBO, J. K. (org.).Brasília: MEC/UNESCO, 2010.

MIGNOLO, Walter D. Histórias locais/projetos globais: colonialidade, saberes subalternos e pensamento liminar. Tradução de Solange Ribeiro de Oliveira. Belo Horizonte: Editora UFMG, 2003.

MIGNOLO, Walter D. Desobediência epistêmica: a opção descolonial e o significado de identidade em política. Cadernos de Letras da UFF - Dossiê: Literatura, língua e identidade, n. 34, p. 287-324, 2008.

LOPES, A. C. Políticas curriculares: continuidade ou mudança de rumos? Revista Brasileira de Educação, p. 109-1 18, 2004.

MARQUEZ, S. C.; PINHEIRO, J. S.; SANTOS, E. S.; SILVA, R. M. G. Tendências atuais da pesquisa em ensino de história e cultura afro-brasileira no ensino de química. In: XVIII Encontro Nacional de Ensino de Química (XVIII ENEQ) Florianópolis, SC, Brasil - 25 a 28 de julho de 2016.

MARTINS, I. Analisando livros didáticos na perspectiva dos Estudos do Discurso: compartilhando reflexões e sugerindo uma agenda para a pesquisa. Pro-Posições, v. 17, n. 1, jan./abr 2006.

MARTINS, L. A fina lâmina da palavra. O Eixo e a Roda: Revista de Literatura Brasileira, Belo Horizonte, v. 17, p. 55-84, 2007.

MOREIRA, P. F. S. D.; RODRIGUES FILHO, G. R. FUSCONI, R.; JACOBUCCI, D. F. C. A bioquímica do candomblé - possibilidades didáticas de aplicação da lei federal 10.639/03. Química Nova na Escola v. 33, p. 85-92, 2011.

MUNANGA, K. Negritude: usos e sentidos. 3. ed. Belo Horizonte: Autêntica, 2012.

MUNANGA, K. A difícil tarefa de definir quem é negro no Brasil - Entrevista de Kabengele Munanga. ESTUDOS AVANÇADOS 18 (50), p. 51-56, 2004.

PEREIRA, A. A.; MONTEIRO, A. M. (Orgs.). Ensino de história e cultura afrobrasileiras e indígenas. Rio de Janeiro: Pallas, 2013.

PINHEIRO, J. S.; SILVA, R. J. G. Aprendizagem de um grupo de futuros professores de Química na elaboração de conteúdos pedagógicos digitais no contexto da obrigatoriedade do ensino da Cultura e História Afro- 
Brasileira e Africana estabelecida pela Lei Federal 10.693/03. Revista Brasileira de Pesquisa em Educação em Ciências, v. 10, n. 2, 2010.

QUIJANO, A. Colonialidade, poder, globalização e democracia. Novos Rumos, n. 17, p. 4-28, 2002.

RIBEIRO, D. O Povo Brasileiro: A formação e o sentido de Brasil. $2^{a}$ ed. São Paulo: Companhia das Letras, 1995.

RIO DE JANEIRO (Estado). Secretaria de Estado de Educação. Currículo Mínimo 2012: QUÍMICA. Rio de Janeiro, 2012.

SANTOS, B. S.; MENESES, M. P. (Orgs.) Epistemologias do Sul. São. Paulo: Almedina, 2009a.

SANTOS, B. S. Direitos Humanos: o desafio da interculturalidade. Revista Direitos Humanos. n. 2, junho, p. 10-18, 2009b.

SANTOS, E. S.; RODRIGUES FILHO, G. e AMAURO, N. Q. Dificuldades na aplicação de materiais didáticos digitais que trabalham assuntos estudados pela química em conformidade com a Lei $n^{\circ} 10.639 / 03$. In: Atas do IX Encontro Nacional de Pesquisa em Educação em Ciências - IX ENPEC Águas de Lindóia, SP, 2013.

SCHAAN, D. P. Cultura Marajoara. Senac Nacional, Rio de Janeiro, 2009.

SERRANO, C. Símbolos do poder nos provérbios e nas representações gráficas MabayaManzangu dos Bawoyo de Cabinda-Angola. Revista do Museu de Arqueologia e Etnologia, n. 3, p. 137-146, 5 dez. 1993.

SILVA, G. R.; FARIAS, L. M. S.; SILVA, R. C. M. Desconstruindo elementos de um modelo epistemológico dominante no ensino de matemática: em busca de um modelo de referencia fundamentado nas contribuições das populações diaspóricas e na lei 10639/2003. Revista da Associação Brasileira de Pesquisadores/as Negros/as (ABPN), [S.I.], v. 9, n. 22, p. 176-190, jun. 2017.

SILVA, J. P.; ALVINO, A. C. B.; SANTOS, M. A.; SANTOS, V. L.; BENITE, A. M. C. Tem dendê, tem axé e tem química: Sobre história e cultura africana e afrobrasileira no ensino de química. Química Nova na Escola, v. 39, n. 1, p. 19-26, 2017.

UNIVERSIDADE FEDERAL DO RIO GRANDE DO SUL. Cerâmicas. Disponível em: <http://www.ufrgs.br/acervoartes/glossario/ceramica>. Acesso: 11 janeiro de 2018.

Recebido em: 26 de fevereiro de 2019

Aprovado em: 30 de agosto de 2019 